\title{
PERFIL HIGIÊNICO SANITÁRIO DE POLPAS DE FRUTAS PRODUZIDAS EM COMUNIDADE RURAL E OFERECIDAS À ALIMENTAÇÃO ESCOLAR
}

\section{HYGIENIC HEALTH PROFILE OF PULP FRUIT PRODUCED IN RURAL COMMUNITY AND OFFERED A SCHOOL LUNCH}

\author{
Denialy Pinto dos Santos ${ }^{1}$ Bruno de Cássio Veloso de Barros ${ }^{2}$ \\ ${ }^{1}$ Universidade Federal do Pará - UFPA - Belém - Brasil denialy_go@ hotmail.com \\ ${ }^{2}$ Universidade Federal do Pará - UFPA - Belém - Brasil brunocvb@ yahoo.com
}

\section{Resumo}

A produção de polpas de frutas congeladas tem se destacado como uma importante alternativa para o aproveitamento dos frutos durante a safra, permitindo a estocagem das polpas fora da época de produção dos frutos in natura. As pequenas fábricas de polpas de frutas têm atraído a atuação de pequenos produtores rurais, por exigirem investimentos relativamente baixos $e$ minimizarem as perdas de matéria-prima nos períodos de safra, possibilitando a verticalização da produção e maior valor agregado ao produto a ser comercializado. O processamento das frutas para obtenção de polpas deve apresentar-se dentro dos padrões de higiene e qualidade, sendo indispensável a adoção de Boas Práticas de Fabricação. Desta forma, o presente estudo objetivouse em analisar o perfil higiênico sanitário de polpas de frutas produzidas em comunidade rural e oferecidas à alimentação escolar. As amostras foram coletadas no município de Paragominas - PA e submetidas às análises físico-químicas de $\mathrm{pH}$, acidez em ácido cítrico, análises sensorial $e$ microscópica e promoveu-se as análises microbiológicas de pesquisa de Salmonella spp. e coliformes totais. Os resultados revelaram que as amostras encontravam-se impróprias para o consumo devido a contaminação de coliformes totais $N M P<3 / g, 100 \%$ das amostras apresentaram ausência de salmonella spp., apenas uma amostra apresentou pH igual a 4,5 as demais apresentaram valores inferiores a 4,5, o que permite classificá-las como ácidas. Todas as amostras apresentavam aspecto satisfatório quanto a cor, odor, aparência e sabor estavam em conformidade com relação à Instrução Normativa $n^{\circ}$ 01, de 7 de Janeiro de 2000 e isentas de sujidades e elementos histológicos.

Palavras-chave: higiene; polpa de fruta; microbiologia; condições sanitárias da produção.

\section{Introdução}

As frutas, pelo valor nutritivo que lhes é atribuído, são indispensáveis à boa alimentação, sendo a melhor forma de seu consumo in natura, quando os alimentos apresentam ausência ou reduzida carga de microrganismos patogênicos ao ser humano (REINHARDT, 1996). 
Alimentos de origem vegetal, por exemplo, as frutas, têm grande importância na nutrição humana devido ao grande conteúdo de vitaminas e sais minerais (NASCIMENTO et al., 2002).

A ocorrência e multiplicação de microrganismos no meio ambiente são comuns e as reações químicas e enzimáticas associadas a eles resultam em decomposição de materiais, inclusive alimentos. Essa decomposição causa modificações na aparência, sabor, textura, cor, consistência e qualidade nutricional do produto. Além disso, certos microrganismos são patogênicos para o ser humano, podendo causar infecções ou toxinfecções quando proliferam em alimentos. Portanto, exceto em fermentações microbiológicas úteis, o desenvolvimento de microrganismos em alimentos é indesejável, sendo necessário evitá-lo ou inibi-lo por meio de métodos de conservação (SOFOS, 1995).

O processamento de frutas para obtenção de polpas é uma atividade agroindustrial importante, na medida em que agrega valor econômico à fruta, evitando desperdícios e minimizando perdas que podem ocorrer durante a comercialização do produto in natura. A polpa de fruta pode substituir a fruta in natura no preparo de sucos, néctares, doces, geléias, sorvetes, baby foods, apresentando a vantagem de ser encontrada também no período de entressafra dessas frutas (FEITOSA, 1999).

Segundo a legislação brasileira do Ministério da Agricultura (Instrução Normativa $\mathrm{n}^{\circ}$ 01, de 07 de janeiro de 2000), "polpa é o produto não fermentado, não concentrado, não diluído, obtido pelo esmagamento de frutos polposos através de processo tecnológico adequado, com teor mínimo de sólidos totais, proveniente da parte comestível do fruto" (BRASIL, 2000). Além disso, devem ser preparadas com frutas sãs, limpas, isentas de matéria terrosa, isenta de partes não comestíveis da mesma, parasitas e detritos de animais ou vegetais. Não deverão conter fragmentos das partes não comestíveis da fruta, nem substâncias estranhas à sua composição normal, devendo ser observada também a presença ou ausência de sujidades, parasitas e larvas (SANTOS et al.).

No Brasil, a polpa industrializada destina-se principalmente à produção de sucos concentrados para o abastecimento dos mercados internos e externos, destinados a residências, hospitais, restaurantes, lanchonetes, alimentação escolar, entre outros, e desperta grande interesse no contexto de desenvolvimento da agroindústria brasileira e mundial, devido ao grande crescimento da demanda internacional por estes produtos (FERNANDES e SILVA).

No entanto, na região norte do Brasil, as unidades produtoras são, na grande maioria, constituídas por pequenos produtores, que utilizam processos quase sempre artesanais, muitas vezes, pelo desconhecimento das boas práticas de fabricação sendo o processamento da polpa de fruta muitas vezes conduzido sem os cuidados de higiene necessários, o que compromete a qualidade do produto final. 
As frutas com atividade de água superior a 0,98 são mais susceptíveis à deterioração por bactérias, fungos e leveduras. Com isso, as análises microbiológicas dessas polpas de frutas são de fundamental importância para avaliação da sua qualidade (ABREU, 2003). As polpas de frutas têm como características gerais, alta atividade de água $(>0,95)$, potencial de óxido redução elevado e pH baixo, sendo a acidez um fator de inibição da microbiota deteriorante (LEITÃO, 1968). Os padrões microbiológicos para polpas de frutas, estabelecidos pela Instrução Normativa $\mathrm{N}^{\circ} 01$ de 07/01/2000, são ausência de Salmonella em $25 \mathrm{~mL}$ e tolerância de no máximo 1/g NMP de coliformes a $45{ }^{\circ} \mathrm{C}$.

Para reduzir a perda da qualidade por fermentação ou outras alterações químicas e biológicas, as frutas deveriam ser processadas imediatamente ou armazenadas sob refrigeração (OLIVEIRA et al., 1999). De acordo com Association of Official Analytical Chemistry matérias estranhas são conceituadas como qualquer material que não seja inerente ao produto, quer seja associado a condições ou práticas inadequadas de produção, estocagem ou distribuição, incluindo sujidades, material decomposto e miscelâneas ou outras substâncias, excluindo-se as contagens bacterianas.

Considerando os aspectos citados, o presente estudo teve como objetivo avaliar o perfil higiênico sanitário das polpas congeladas de goiaba (Psidiumguaiajava, L.), acerola (Malpighia, spp.) e maracujá (Passiflora, spp.) produzidas e comercializadas no município de Paragominas Pará, verificando suas adequações em relação aos padrões de identidade e qualidade para polpa de frutas, conforme descrito na Instrução Normativa n ${ }^{\circ} 01$, de 7 de janeiro de 2000.

\section{Material e métodos}

\section{Coleta e armazenamento das amostras}

A coleta das amostras de polpas de frutas congeladas foi realizada aleatoriamente em diferentes pontos de comercialização no Município de Paragominas - Pa, sendo as mesmas colocadas em caixas isotérmicas, contendo gelo e acondicionadas em freezer para posteriores análises no Laboratório de Microbiologia de Alimentos do Laboratório Central do Estado do Pará LACEN - PA, onde foram realizadas as análises preconizadas pela Instrução Normativa $n{ }^{\circ} 01$, de 7 de janeiro de 2000 e Legislação RDC n. 12 da ANVISA/MS (BRASIL, 2001).

Foram analisadas 06 amostras de polpa de frutas congeladas, em embalagens de 500 gramas, dentro do prazo da data de validade apresentado na embalagem, de apenas uma marca, porém de três sabores distintos. Após as coletas as mesmas foram armazenadas em caixas isotérmicas, contendo gelo e acondicionadas em freezer até o momento do processamento das análises laboratoriais. 


\section{Análise Microbiológica}

No laboratório, cada amostra recebeu um código de identificação. Após o descongelamento das polpas em temperatura a $5{ }^{\circ} \mathrm{C}$, as amostras foram submetidas à pesquisa de Salmonella spp. e determinação do Número Mais Provável (NMP) de coliformes a $45^{\circ} \mathrm{C}$, sendo as análises realizadas por amostra em duplicata, segundo metodologia recomendada pelo Ministério da Agricultura e Agência Nacional de Vigilância Sanitária - ANVISA (BRASIL, 2001). Foram pesadas 25 g de cada amostra e transferidas assepticamente para frascos contendo $225 \mathrm{~mL}$ de água peptonada estéril (diluição $10^{-1}$ ). A partir dessa diluição, foram feitas as diluições seriadas até $10^{-3}$ com o mesmo diluente (APHA, 1984).

Para a determinação do Número Mais Provável (NMP) de coliformes totais foi utilizada a técnica dos tubos múltiplos, empregando-se o caldo Lauril Sulfato Triptose com incubação a $35{ }^{\circ} \mathrm{C}$ durante 48 horas. A partir dos resultados positivos, provenientes das provas para coliformes totais, foram semeados tubos contendo caldo Escherichia coli (EC) e incubados a $44,5{ }^{\circ} \mathrm{C}$, por 24 a 48 horas.

Na determinação e pesquisa de Salmonella spp. foram utilizados 25 gramas retiradas das respectivas amostras e semeadas em $225 \mathrm{~mL}$ de caldo lactosado e de água peptonada a $1 \%$ sendo posteriormente homogeneizados. Depois promoveu-se a incubação a $35{ }^{\circ} \mathrm{C}$ por 24 horas, sendo retirado da solução: $1 \mathrm{~mL}$ de cada cultivo transferindo-se para tubos de ensaio contendo $10 \mathrm{~mL}$ de caldo tetrationato de Kauffmann e $10 \mathrm{~mL}$ de caldo selenito cistina que foram incubados a $35{ }^{\circ} \mathrm{C}$. Após 24, 48 e 120 horas foram feitas semeaduras, em superfície de placas de Petri contendo ágar Salmonella Shigella e ágar verde brilhante (BRASIL, 1981 e 2003).

\section{Análise Físico-química}

A determinação do pH foi realizada diretamente em um potenciômetro da marca Digimed, modelo DMPH-2, calibrado com soluções tampão pH 4,0 e 7,0. Esta determinação foi feita conforme recomendações do Instituto Adolfo Lutz, 1985.

\section{Análise Microscópica}

As amostras foram submetidas ao método deflutuação para sujidades leves, seguindo recomendações da AOAC, 1984.

\section{Análise Sensorial}

As características sensoriais avaliadas foram: cor, sabor, aparência e odor, segundo a metodologia convencional recomendada pelo Instituto Adolfo Lutz (1985). As características sensoriais constituem em um método subjetivo utilizado para avaliar os alimentos, bebidas e a água. 
Para analisar a aparência das amostras foram observadas as propriedades visíveis como o aspecto, cor, transparência, brilho, opacidade, consistência e características de superfície. Para a análise do sabor das amostras os julgadores tomaram certa quantidade das amostras, sem excessos, e procedeu à deglutição, tomando o cuidado em evitar a fadiga sensorial. Entre uma amostra e outra foi realizada a lavagem da cavidade oral utilizando a água filtrada. Para analisar o odor das amostras os julgadores aproximaram as amostras da narina e realizaram cheiradas curtas, evitando longas inalações que pudessem cansar o olfato pela adaptação.

\section{Resultados e Discussão}

Analisando a tabela 1, observa-se que os resultados das análises das polpas de frutas congeladas para Coliformes a $45{ }^{\circ} \mathrm{C}$, indicados na coluna central, apresentam valores superior a 1 $\mathrm{NMP} / \mathrm{g}$ para todas as amostras, por tanto, fora dos padrões exigidos pela Instrução Normativa $\mathrm{N}$ ${ }^{\circ} 01$, de 07/01/200, de NMP máximo de 1/g, indicando $100 \%$ de contaminação por coliformes fecais $(\mathrm{NMP}<3 / \mathrm{g})$ em relação as amostras de polpas goiaba, acerola e maracujá, mostrando valores superiores aos encontrados por Amorim et al. (2010), que obtiveram valores inferiores a 0,3 NMP/g. Contaminação por coliformes totais e termotolerantes em polpa de maracujá também foi encontrada por Leite et al. (2000) e Lima et al. (2001), estando, provavelmente, associada à manipulação inadequada durante o processamento da matéria-prima, ou à contaminação de equipamentos.

A terceira coluna apresenta os resultados das análises microbiológicas para determinação de Salmonella spp, a qual apresentou ausência do microrganismo em $25 \mathrm{~g}$ de polpa para todas as amostras analisadas, estando de acordo com o padrão estabelecido pela legislação. Bueno et al. (2002), avaliaram a qualidade microbiológica de 15 marcas de polpas de frutas congeladas de diversos sabores, concluindo que todas as amostras atenderam à legislação vigente.

Tabela 1 - Resultados das análises microbiológicas para Coliformes a $45^{\circ}$ e Salmonella spp. das polpas de frutas congeladas produzidas em Paragominas - PA, 2010.

\begin{tabular}{c|c|c}
\hline Polpas & $\begin{array}{c}\text { Coliformes a 45 }{ }^{\circ} \mathbf{C} \\
\text { (NMP/g) }\end{array}$ & $\begin{array}{c}\text { Salmonellaspp } \\
(-/+)\end{array}$ \\
\hline Goiaba - A01 & $<3 / g$ & - \\
Goiaba - A02 & $<3 / \mathrm{g}$ & - \\
Acerola - A01 & $<3 / \mathrm{g}$ & - \\
Acerola - A02 & $<3 / \mathrm{g}$ & - \\
Maracujá - A01 & $<3 / \mathrm{g}$ & - \\
Maracujá - A02 & $<3 / \mathrm{g}$ & - \\
Padrão Federal $*$ & máximo $1 / \mathrm{g}$ & Ausência em $25 \mathrm{~g}$ \\
\hline
\end{tabular}

*Instrução normativa ${ }^{\circ}$ 01, de 7 de Janeiro de 2000; NMP/g= Número Mais Provável por g.

Fonte: LACEN PA, 2010. 
A tabela 2 apresenta os resultados para análise microscópica sobre a presença de sujidades e/ou elementos histológicos nas polpas de frutas, podemos perceber que a coluna central, referente a sujidades, não indica qualquer presença de tais substâncias nas amostras, sendo um ótimo indicativo para técnicas corretas em um dos processos, o de filtragem. Na terceira coluna, referente aos elementos histológicos, também não temos variações, uma vez que temos resultados para ausência. Assim, 100\% das amostras encontraram-se de acordo com os padrões estabelecidos pela legislação vigente. Em contra partida, Pereira et al. (2006), ao analisarem polpas de frutas congeladas e comercializadas em Viçosa-MG, constataram que algumas amostras foram classificadas como inaceitáveis para o consumo, pois foram encontrados fragmentos de insetos/larvas nas polpas de caju (marcas A e C), goiaba (marca B) e graviola (marca A).

Tabela 2 - Resultados da análise microscópica das polpas de frutas congeladas produzidas em Paragominas - PA, 2010.

\begin{tabular}{c|c|c}
\hline Polpas & Sujidades & Elementos Histológicos \\
\hline Goiaba - A01 & Ausência & Ausência \\
Goiaba - A02 & Ausência & Ausência \\
Acerola - A01 & Ausência & Ausência \\
Acerola - A02 & Ausência & Ausência \\
Maracujá - A01 & Ausência & Ausência \\
Maracujá - A02 & Ausência & Ausência \\
\hline
\end{tabular}

Fonte: LACEN - PA, 2010.

Os resultados da tabela 3 referem-se às análises físico-químicas que incluem análise de $\mathrm{pH} \mathrm{e}$ Acidez em ácido cítrico. Observa-se, na segunda coluna, que as variáveis para pH, com exceção da amostra Goiaba - A01, as demais apresentaram valores de $\mathrm{pH}$ inferiores a 4,5, o que permite classificá-las como ácidas, característica que desfavorece o desenvolvimento de bactérias, a exceção daquelas ácido-tolerantes (EIROA,1989). O mesmo foi observado por Santos et al. (2008), que obtiveram valores de 3,2 e 2,8 para polpas de Acerola e Maracujá, respectivamente.

Analisando a presença de acidez em ácido cítrico, na terceira coluna, apenas a amostra Maracujá - A01 encontrava-se com valor inferior ao padrão mínimo estabelecido, como mostram os Valores de Referência pré-estabelecidos na última coluna da mesma tabela. As demais amostras apresentaram valores acima do padrão mínimo estabelecido pela IN n ${ }^{\circ} 01$, de 7 de janeiro de 2000 , isto explica-se pelo grau de amadurecimento do fruto, uma vez que, à medida que ocorre o amadurecimento, o teor de ácido cítrico diminui.

Na tabela 4 encontram-se os resultados da análise sensorial das polpas de frutas, analisando a aparência, a cor, o sabor e o odor. Observou-se que todas as amostras apresentaram condições satisfatórias para os caracteres organolépticos estudados, 100\% das amostras também se 
apresentaram de acordo com o padrão estabelecido pela Instrução Normativa n ${ }^{\circ} 01$, de 7 de Janeiro de 2000.

Tabela 3 - Resultados das análises físico-químicas das polpas de frutas congeladas produzidas em Paragominas - PA, 2010.

\begin{tabular}{c|c|c|c}
\hline Polpas & pH & Acidez Em Ácido Cítrico & *VR mín. p/ Ac. em Ác. Cítrico \\
\hline Goiaba - A01 & 4,5 & 0,52 & 0,4 \\
Goiaba - A02 & 4,4 & 0,5 & 0,4 \\
Acerola - A01 & 4,13 & 1,07 & 0,8 \\
Acerola - A02 & 4,25 & 0,89 & 0,8 \\
Maracujá - A01 & 3,81 & 2,24 & 2,5 \\
Maracujá - A02 & 3,7 & 2,77 & 2,5 \\
\hline
\end{tabular}

*Valor de Referência Mínimo para Acidez em Ácido Cítrico.

Fonte: LACEN - PA, 2010.

Tabela 4 - Resultados da análise sensorial das polpas de frutas congeladas produzidas em Paragominas - PA, 2010.

\begin{tabular}{|c|c|c|c|}
\hline Polpas & APARÊECIA & COR & ODOR / SABOR \\
\hline Goiaba - A 01 & Satisfatória & Vermelho & Próprio \\
\hline Goiaba - A 02 & Satisfatória & Vermelho & Próprio \\
\hline Acerola - A 01 & Satisfatória & Vermelho & Próprio \\
\hline Acerola - A 02 & Satisfatória & Vermelho & Próprio / Ácido \\
\hline Maracujá-A 01 & Satisfatória & Amarelo & Próprio / Ácido \\
\hline Maracujá-A 02 & Satisfatória & Amarelo & Próprio / Ácido \\
\hline
\end{tabular}

Fonte: LACEN - PA, 2010.

\section{Conclusão}

Os resultados das análises consideradas para o presente estudo, demonstraram ausência de salmonella spp., portanto as amostras apresentaram-se dentro dos padrões aceitáveis e préestabelecidos pela legislação vigente. A análise, referente ao $\mathrm{pH}$ das amostras, revelou que apenas uma amostra apresentou valor de $\mathrm{pH}$ igual a 4,5, as demais caracterizaram-se como ácidas com $\mathrm{pH}$ $<$ 4,5. As análises de condições sensoriais (cor, aparência, odor e sabor) e análise microscópica consideradas, apresentaram-se com caráter satisfatório e ausência de sujidades e/ou elementos histológicos, respectivamente para $100 \%$ das amostras analisadas no presente estudo, desta forma, encontram-se dentro dos padrões pré-estabelecidos pela Instrução Normativa ${ }^{\circ} 01$, de 7 de Janeiro de 2000 e isentas de perigos físicos e biológicos, o que poderiam comprometer a integridade do alimento e a segurança, integridade física e saúde do consumidor.

As análises para Coliformes Fecais apontaram resultados de impropriedade para o consumo, tendo em vista que a mesma não seguiu a quantidade tolerável para a presença do microrganismo na amostra, acusando um valor de NMP inferior a 3/g. Baseando-se na Instrução Normativa $n^{\circ} 01$, de 7 de Janeiro de 2000, esses valores não devem ser superiores a 1NMP/g, logo tal produto 
comercializado classifica-se como impróprio para consumo humano, sugere-se que tal conclusão seja proveniente de uma má procedência na fabricação do mesmo, apontando precariedades nos processos da linha de produção, manipulação inadequada da matéria prima, condições de higiene insatisfatórias, entre outras técnicas inadequadas, sendo assim desconsiderando as Boas Práticas de Manipulação.

É de extrema relevância, considerar que tais técnicas que irão garantir a seguridade do alimento sejam adotadas em todas as etapas dos processos para a obtenção do produto final, uma vez que serão estas que irão classificar o alimento como apto ou não para consumo, ou seja, isento de qualquer perigo químico, físico e/ou biológico que possam vir a comprometer a saúde e a integridade física do consumidor, justificando assim fiscalizações feitas por órgãos públicos responsáveis (ANVISA) garantindo assim melhorias em relação à qualidade higiênica sanitária das polpas frutas congeladas produzidas e oferecidas no município estudado.

\begin{abstract}
The production of frozen fruit pulp has emerged as an important alternative to the use of the fruits during the harvest, allowing the storage of the pulp out of seasont. The small fruit pulp mills have attracted the performance of small farmers, because they require relatively low investments and minimize losses of raw materials during the harvest period, allowing the vertical integration of production and higher value added to the product being marketed. The processing of fruits to obtain pulp must be submitted within the standards of hygiene and quality, which needs the adoption of Good Manufacturing Practices. The objective of this study to analyze the hygienic sanitary profile of fruit pulp produced in the rural community and offered schools. The samples were collected Paragominas - PA and subjected to physical and chemical analysis of pH, acidity in citric acid, sensory and microscopic analysis promoted to the microbiological testing of Salmonella spp and coliforms. The results showed that the samples were unfit for consumption because of contamination by coliform MPN $<3 / \mathrm{g}, 100 \%$ of samples showed absence of Salmonella spp., only one sample showed $\mathrm{pH}$ of 4.5 the others showed values less than 4.5, which allows to classify them as acidic. All samples showed satisfactory appearance, color, smell and flavor in accordance with Instruction No. 01, from January 7, 2000 and free of dirt and histological elements. It was concluded that samples of pulp were considered in relation to acidic $\mathrm{pH}, 100 \%$ of the samples were within the standards established by law in relation to Salmonella spp. but considered unfit for consumption due to a contamination by fecal coliforms, this contamination can be justified due to the limited production line, where we have not taken into account Good Practices of Manipulation.
\end{abstract}

Key-words: Hygiene; fruit pulp; Microbiology; Sanitary conditions of production.

\title{
Referências
}

ABREU, M. C.; NUNES, I. F. S.; OLIVEIRA, M. M. A. Perfil microbiológico de polpas de frutas comercializadas em Teresina, PI. Higiene Alimentar, v. 17, n. 112, p. 78-81, 2003.

AMERICAN PUBLIC HEALTH ASSOCIATION - APHA. Compendium of methods for the microbiological examination of foods.2. ed.Washington, D.C., 1984. 
AMORIM, G. M.; SANTOS, T. C.; PACHECO, C. S. V.; TAVARES, I. M. C.; FRANCO, M. Avaliação Microbiológica, Físico-química e sensorial de polpas de frutas comercializadas em Itapetinga-BA. Enciclopédia Biosfera, Centro científico Conhecer - Goiânia, v. 6, n. 11, p. 1-8, 2010.

ASSOCIATION OF OFFICIAL ANALYTICAL CHEMISTRY - AOAC. Extraneous materials. In: Official methods of analysis.14th ed. Washington, D.C., 1984. p. 1141 (Tec. 44.002).

BRASIL. MINISTÉRIO DA AGRICULTURA. Secretaria Nacional de Defesa Agropecuária. Métodos analíticos oficiais para o controle de produtos de origem animal e seus ingredientes. I. Métodos microbiológicos. Brasília, 1981.

MINISTÉRIO DA AGRICULTURA. Instrução Normativa No 01, de 07/ 01/ 2000 - MAPA. (Ministerio da Agricultura Pecuária e do Abastecimento).

MINISTÉRIO DA AGRICULTURA DO ABASTECIMENTO. Instrução Normativa no 12/99, de 13/09/99. Padrões de Identidade e Qualidade para Polpas de Frutas. Diário Oficial da República Federativa do Brasil, Brasília, DF, 13 set. 1999, Seção I, p 72, 2000.

MINISTÉRIO DA AGRICULTURA, PECUÁRIA E ABASTECIMENTO. Secretaria de Defesa Agropecuária. Instrução Normativa n. 62, de 26 de agosto de 2003. Oficializa os métodos analíticos oficiais para análises microbiológicas para controle de produtos de origem animal e água. Diário Oficial da República Federativa do Brasil, Brasília, DF, 18 de setembro de 2003, seção 1, p. 14.

AGÊNCIA NACIONAL DE VIGILÂNCIA SANITÁRIA. Resolução RDC no 12, de 02/01/2001. Regulamento Técnico sobre padrões microbiológicos para alimentos. Diário Oficial da República Federativa do Brasil, Brasília, DF, 10 jan. 2001, Seção I, p. 45-53.

BUENO, S. M.; GRACIANO, R. A. S.; FERNANDES, E. C. B.; GARCIA-CRUZ, C. H. Avaliação da qualidade de Polpas de Frutas Congeladas. Revista Instituto Adolfo Lutz, v. 62, n. 2, p. 121-126, 2002.

EIROA, M. N. U. Microrganismos deteriorantes de suco de frutas e medidas de controle. Boletim da Sociedade Brasileira de Ciência e Tecnologia de Alimentos, v. 23, n. 3/4, p. 141-160, 1989.

FEITOSA, T.; BASTOS, M. S. R.; OllVEIRA, M. E. B.; MUNIZ, C. R.; LEMOS, T. O.; OLIVEIRA, S. C. A. Avaliação microbiológica e microscópica em polpa de frutas tropicais. Boletim da Sociedade Brasileira de Ciência e Tecnologia de Alimentos, v. 33, n. 1, p. 35-37, 1999.

FERNANDES, A. R.; SILVA, C. A. B. Projetos de Empreendimentos Agroindustriais: Produtos de origem vegetal. Viçosa: Universidade Federal de Viçosa, v.2, 2003.

INSTITUTO ADOLFO LUTZ - IAL. Normas Analíticas do Instituto Adolfo Lutz. V. 1: Métodos químicos e físicos para análise de alimentos, 3. ed. São Paulo: IMESP, 1985.

LEITÃO, M. F. F. Microbiologia de sucos e produtos ácidos. Boletim do ITAL, Campinas, v. 15, p. 1-15, 1968.

LEITE, C. C.; SANTANA, L. R. R.; SILVA, M. D.; SANT'ANNA, M. E. B.; ASSIS, P. N. Avaliação Microbiológica de polpas congeladas de frutas produzidas no Estado da Bahia. Higiene Alimentar, v. 11, n. 78-79, p. 69-73, 2000.

LIMA, J. R.; MARTINS, S. C. S.; SILVA, J. L. A. Avaliação de polpas de frutas congeladas comercializadas no estado do Ceará através de indicadores microbiológicos. Higiene Alimentar, v. 15, n. 88, p. 62-66, 2001.

NASCIMENTO, A. R.; FERREIRA FILHO, F.; MOUCHREK FILHO, J. E.; CANTANHEBE, F. B. Perfil microbiológico das polpas de acerola (MalpighiaglabaL) 127 e abacaxi (Ananascomosus), produzidas e comercializadas na ilha de São Luís, MA. Higiene Alimentar, v. 13, n. 62, p. 44-47, 2002.

OLIVEIRA, M. E. B; BASTOS, M. S. R; FEITOSA, T. Avaliação de parâmetros de qualidade físico-químicos de polpas congeladas de acerola, cajá e caju. Ciência e Tecnologia de Alimentos, v. 19, n. 3, p. 101-106, 1999. http://dx.doi.org/10.1590/S0101-20611999000300006 
PEREIRA, J. M. A. T. K.; OLIVEIRA, K. A. M.; SOARES, N. F. F.; GONÇALVES, M. P. J. C.; PINTO, C. L. O.; FONTES, E. A. F. Avaliação da qualidade físico-química, microbiológica e microscópica de polpas de frutas congeladas comercializadas na cidade de Viçosa. Alimentação e Nutrição, v. 17, n. 4, p. 437-442, 2006.

REINHARDT, D. H. Avanços tecnológicos na fruticultura tropical. Informativo da Sociedade Brasileira de Fruticultura, v. 15, n. 4, p. 18-21, 1996.

SANTOS, F. A.; SALLES, J. R. J.; CHAGAS FILHO, E.; RABELO, R. N. Análise qualitativa de polpas congeladas de frutas produzidas pelo SUFRUTS, MA. Higiene Alimentar, v. 15, n. 119, p. 14-22, 2004.

SANTOS, C. A. A.; COELHO, A. F. S.; CARREIRO, S. C. Avaliação microbiológica de polpas de frutas congeladas. Ciência e Tecnologia de Alimentos, v. 28, n. 4, p. 913-915, 2008. http://dx.doi.org/10.1590/S010120612008000400023

SOFOS, J. N. Antimicrobial Agents. In: MAGA, J. A. \& TU, A. T. (Eds.) Food Additive Toxicology. New York: Marcel Dekker Inc. p. 501-529, 1995.

Submetido em 22 jun 2011, Aceito para publicação em 22 mai 2012. 